\title{
'Stratification Philosophy' and Collective Action: Situating Poverty Attribution within the Five Stage Model of Intergroup Relations
}

\author{
Dr Kehinde D. Ige \\ Department of Sociology, University of Zululand, South Africa \\ E-mail: igedavies@gmail.com
}

Doi:10.5901/mjss.2014.v5n8p490

\begin{abstract}
Scholars have grappled with the paradox of how disadvantaged groups or persons cope with a system in which they are disadvantaged. There have therefore been different perspectives to understand how systems of inequality are legitimized. In a survey of slum dwellers in Lagos ( $n=383$ ), and adopting an integration of Relative Deprivation Theory, Social Identity Theory and The Five Stage Model of Intergroup Relations (FSM), the study attempted to decipher the role of poverty attribution in shaping reaction to inequality on the basis of feelings of injustice. The Multivariate Analysis of Covariance (MANCOVA) showed in line with the FSM that reaction o inequality was predicated upon perceived causes of poverty. It was therefore concluded that along with instrumental and affective concerns, beliefs about causes of poverty represent an additional pathway in explaining motivations and impediments to the actions of disadvantaged persons and groups when faced with inequality or injustice.
\end{abstract}

Keyword: Protests; Marginalization; deprivation; inequality; injustice.

\section{Introduction}

The phenomenon of different reaction by people to inequality and deprivation in society has interested recent scholars (Szirmai, 1991: 232). Olsen's (1968) 'dilemma of protest' and its consequence of 'free ride' for rational actors probably partly answer the questions relating to rational inhibition to protest. Relative Deprivation (RD) research showed that while perception or individual of Egoistic Relative Deprivation (ERD) is linked to individual reaction, collective action is predicated upon perception of group-based or Fraternal Relative Deprivation (FRD). However, RD research has failed to predict which group member will be more likely to embark on action given that disadvantaged persons often fail to act in spite of feelings of FRD (Klandermans, 2002; Wright et al., 1990; Brush, 1996). Olsen (1968) provided the framework for the 'dilemma of protest' when he proposed that rational actors will take a 'free ride' where benefits of collective action becomes available to all regardless of their extent of participation. Scholars have argued that while Olsen's proposition enables our understanding of why people may not react to injustice, it does not shed light on why others do, or the range of possible actions. This dilemma has been at the centre of a large body of research that attempts to unravel the conditions under which aggrieved persons or groups will or will not react to injustice.

While scholars are in agreement that relative deprivation stimulate feelings of anger or outrage in the aggrieved which they often need to remove by restoring justice, different pathways have been adduced through which the injured will be motivated to act or not. The resource mobilization and political process school (McCarty \& Zald, 1977) argued that reaction is contingent upon availability of resources, conceiving of injustice feelings as ubiquitous. Recently however, students of collective action integrating Social Identity Theory (SIT) with Relative Deprivation (RD) theory have explained motivations and reaction to deprivation in terms of distinct pathways through which our understanding of motivation to act can be enhanced. While Klandermans (2002) argued for a pathway entailing instrumentality (cost benefit analysis, 'efficacy') and group identification, Stürmer and Simon (2008) classified motivation according to an 'affective' and 'identification' distinction. However, recently, Simon et al (2009) argued for an additional 'emotion' pathway. Others Scholars have argued for supplementary pathways including efficacy (van Zomeren et al., 2010; Giguère \& Lalonde, 2010), willingness to express one's view or ideology, the protection of sacred values (van Stekelenburg et al., 2009; Ginges \& Altran, 2009) and individual enhancement motive (Tropp \& Brown, 2004). However empirical support for these models has been weak as statistical variance contributed to reaction by instrumentality, efficacy and identification have been mediocre (Bluic et al., 2007).

The social movement literature has however downplayed the role of attitudes and consensually shared beliefs as motivators or impediments to mobilization to redress for grievances. However, matters of attitude are creeping back in the 
forms of logics, frames and discourse that spur micro-mobilization (Rothenberg, Skully \& Tang, 2002). In addition recent studies have ignored the need to study action as it occurs in a continuum (Wright et al., 1990) from acceptance to the most radical forms of action. To account for 'missing' variance it therefore becomes necessary to study all dimensions of action and other possible impediments and motivators aside from instrumental and affective concerns. As Ginges \& Altran (2009) argued, the current empirical evidence available does not support the continued insistence on instrumental concerns. van Stekelenburg et al (2009) also noted that SIT's reduction of motivations for collective action to rational processes neglects other equally important reasons why people do or do not react to injustice. Bullock (2006) argued that attribution beliefs may affect interpersonal and intergroup behaviour, political mobilization and ultimately the maintenance or challenge to discrimination, injustice and economic inequality beyond their applications to issues relating to policy preferences and affirmative action. There is much to be learnt therefore from the prevalence, dynamics, and consequences of legitimizing ideologies, particularly the processes that contribute to critical resistance among disadvantaged groups especially in terms of developing counter-hegemonic frameworks (Bullock, 2006). The question the present study attempts to answer therefore is 'how then does attribution fit into the reaction to injustice framework'? Or how does attribution of causes of poverty hinder or motivate the deprived persons' reaction?

\subsection{Motivations and Constraints to the Deprived Actor}

While recent theories in the intergroup relations literature attempt to extrapolate their findings to the dynamics of responses to injustice, the attempts have been reductionist in that they often explicitly focus either on collective or individualistic responses to inequality without integrating how actions proceed in a continuum (Taylor \& Moghaddam, 1987). Thus, their postulations are incapable of grasping all dimensions of disadvantaged-group behavior. Wright et al (1990) argued that these theories (RD, Equity, Distributive justice) failed to provide adequate insights into when disadvantaged group members will choose either individual or collective action, or when actions will be normative or nonnormative. While Runciman's distinction of ERD and FRD leading to individual and collective action respectively seemed to solve the puzzle, there is evidence that the personal-collective distinction presents challenges in conceptualization and operationalization (Martin et al., 1984). When researchers used appropriate conceptual constructs, the link to action remains a 'trouble spot' (Wright et al., 1990; Martin, 1986).

However, the introduction of Social Identity Theory (SIT) (Tajfel \& Turner, 1979) seemed to ameliorate the situation. SIT proposes three strategies available to disadvantaged groups and persons to respond to their situation; individual mobility entailing attempts to join the high status group or social competition involving collective action to change inter-group situation. A third option proposed entails 'social creativity' entailing a reappraisal of intergroup comparison in favour of the in-group. SIT proposes that the choice of option is contingent upon the perceived permeability, stability and legitimacy of intergroup boundaries (Boen \& Vanbeselaere, 2002: 300). These conditions have been empirically verified by Ellemers et al (1993) who concluded that disadvantaged group members often chose action based on pragmatism (Ellemers et al., 1993: 777), but found no evidence supporting legitimacy. Ellemers and her colleagues concluded that while justice considerations influence people's evaluation of the situation, it does not influence choice of action. This finding challenged the widely held theses of SIT and RD that reaction is contingent upon injustice feelings, while supporting the Resource Mobilization model and its claims of calculated rationality as the basis for action, with injustice feelings as post hoc rationalizations (Martin, 1986). This necessitated a reformulation of RD (Boen \& Vanbeselaere, 2002: 301) and a reemphasis of the operationalization of RD to incorporate Runchiman's (1966) referential thesis and SIT. Thus recent studies show that group deprivation predicts collective action. The work of Mummendey et al (1999) showed that factors proposed by SIT best predicted individual strategies, whilst those derived from RDT better accounted for collective actions thus combining SIT and RDT enhanced predictability (Boen \& Vanbeselaere, 2002: 302), bypassing the problem earlier posed by the finding of Ellemers et al. (1993).

While SIT has made tremendous impact in predicting action, by identifying instability and illegitimacy as the precursors to the perception of cognitive alternatives and identifying the presence of cognitive alternatives as the determinant of action, it is unable to identify the conditions that will determine which of the alternative responses will ultimately be preferred (Taylor \& Moghaddam, 1987). In addition, SIT is unable to decipher what factors will determine disadvantaged group members' perception of the intergroup situation as illegitimate and unstable and consequently is unable to predict when resultant action will be individual or collective, normative or non-normative (Wright et al., 1990: 995). Taylor \& Moghaddam (1987) argued that SIT does not provide conditions under which alternative responses will be preferred or what variables are responsible for perception of legitimacy or illegitimacy of group boundaries and consequently is unable to decipher when reactions will be individual or collective, normative or non-normative (Wright et al., 1990: 995). Taylor \& McKirnan (1984) consequently proposed that the type and nature of reaction by disadvantaged 
groups is predicated upon the prevalent social philosophy guiding social stratification.

In order to provide a framework that incorporates the distinction between individual and collective actions as well as between normative and non-normative action, a theoretical integration is therefore used in the present study that incorporates the basic reaction model central to RD and its proposition that the deprived actor will react when faced with injustice or when justice norms are violated and SIT's contribution entailing its proposal that action is generally dependent upon awareness of alternatives to the inter-group structure. When these premises are combined with FSM's distinction between actions based on social norms and locus of action, a better explanatory tool is attained. This is especially useful in the present study given that the FSM stages incorporate the dynamics of perception of the overriding philosophy guiding stratification as the cause of changes from one stage to another. These ascription and achievement based philosophies are consistent with the dimensions of perceptions of causes of poverty and as the changes in guiding philosophies proposed by the model are analogous to changes in attribution from fatalistic to individual and structural explanations. Taylor \& McKirnan's (1984) model therefore serves as an appropriate tool for understanding the dynamics of changes in attribution contingent upon deprivation feelings. On the basis of the premise that individual attribution signifies support for the status quo and that structural attribution signifies dissatisfaction with the present social order and is incompatible with collective interest, the FSM provides a useful tool of analysis.

\subsection{Poverty Attribution and the Deprived Actor}

Harper (2003: 200) proposed that social scientific research must extend beyond macro explanations to 'de-mystifying explanations of poverty and exploring their ideological foundations in social context... practically and politically... to contribute toward conscientization in the fight against poverty'. However, much remains to be learned about the prevalence, dynamics, and consequences of legitimizing ideologies, particularly the processes that contribute to critical resistance among both privileged and marginalized groups. The study of attributions must therefore encompass an understanding of how counter-hegemonic frameworks develop. To blame the poor for poverty is to exculpate social and political institutions from the responsibility to ameliorate the conditions of the poor and instead to legitimize cosmetic attempts to moderate attitudes and behavior of the poor (Edelman, 1998: 132).

Beliefs about poverty and the poor are crucial to our understanding of intergroup relations and social inequality (Bullock, 2006). Beyond policy preferences, relatively little research examines the relationship of beliefs about poverty to interpersonal behavior (Bullock, 2006). Studies have been limited to showing cognitive acceptance of 'legitimization myths', without showing how the possession of attitudes translates into action. The most contentious issue in the literature on reaction to inequality is the response of aggrieved persons to feelings of injustice. Social justice theories argue that deprived actors may resort to violence to secure a fairer share of rewards (Gurr, 1970). These theories, assumed that feelings of injustice leads to violent reaction and quite often have not been devoted to adequate empirical test of resultant actions.

The present study hypothesizes that poverty attribution forms a substantial part of factors that prevent or motivate deprived actors from resorting to violent means to seek redress. As Skek (2003: 624) argued, the importance of the view of the poor of causes of poverty cannot be overestimated if perception can be taken to be the basis for decisions and actions. If the poor believe they are poor because of conditions they have no control over, they may become frustrated and despondent (Shek, 2003). If they believe that inequality is the result of a just system of meritocracy, they may accept it (Suhrecke, 2001). However, if the poor attribute poverty to injustice or exploitation, their behavior or action will not be in support of inequality. It seems therefore that there is a relationship between attributions of poverty and legitimization or opposition to social inequality. It is plausible therefore that as perception of causes of poverty affect institutional response to poverty (Lepianka et al., 2009), it equally affects how the poor respond to these policies and their own objective conditions of deprivation, marginalization and disadvantage in line with Bullock's (2006) proposal that these beliefs may affect political mobilization, aspirations, achievement and ultimately, the maintenance of or challenge to discrimination, injustice and economic inequality.

The salience of the introduction of the effects of consensually shared beliefs about causes of poverty as additional pathway for understanding motivations for action using Taylor \& McKirnan's (1984) Five Stage Model (FSM) of intergroup relations is justified on the basis of the fact that the FSM proposes that social change is attained through the dynamics of perceptions of the overriding social philosophy guiding stratification and income distribution (Taylor \& Moghaddam, 1987). Taylor and McKirnan's (1984) FSM builds on SIT's premise that reaction to inequality and disadvantage is contingent upon perception by disadvantaged group members that group boundaries are illegitimate (Tafjel \& Turner, 1979). Thus when entrance to the advantaged group is perceived to be based on personal achievement rather than group membership, disadvantaged people are likely to take individual actions to improve their personal situations. At this stage, 
those successful in making upward mobility or those who did not attempt mobility will endorse the prevailing belief that the system is open, and success is available to anyone with ability. Consequently people are persuaded that they collectively benefit from the present system. However, where people make attempts at mobility and fail, they are likely to reject the status quo and its associated beliefs. The FSM proposes that collective action is associated with the perception that existing social arrangements are unfair and unjust (Moghaddam, Taylor \& Lalonde, 1987: 303). The model proposes that all inter-group relations proceed sequentially through five stages.

\subsection{The present study}

The present study hypothesizes in line with the FSM that the perception of the overriding social philosophy guiding stratification and changes in perceptions from ascription to achievement as guiding principles for income and status distribution in society predicts reaction of disadvantaged persons and groups. At the first stage of the model, stratification is based on ascribed characteristics and immutable. At this stage people attribute disadvantage to forces beyond individual and in fact societal control. Gender and economic status are said to be preordained given the huge impact of religious and non-scientific explanations among disadvantaged groups. Group boundaries are closed as individuals are expected to maintain their ascribed status throughout their lives. Explanation for poverty and disadvantage at this stage is fatalistic. Where fatalistic explanations predominate, people are likely to have low feelings of injustice; consequently, response to disadvantage is often to 'do nothing' or individual normative. In the next stage however, ascribed characteristics are replaced by the philosophy of individualism. At this stage, members of disadvantaged groups perceive that the advantaged group is open and entry is dependent solely on individual abilities and attributes. At this stage advantaged group members make attempts at social mobility thus reaction to inequality is individual normative. The second stage therefore represents the stage where people attribute poverty and disadvantage to individual character deficiencies thus response to inequality is individual. At the third stage however, when repeated attempts at mobility are blocked, disadvantaged groups realize that individual efforts are not enough to gain access to advantaged groups. Individual attributions are abandoned for structural attribution. Consequently, individual action is abandoned in favour of collective action. The proposed relationships are as follows; (a) When disadvantage is perceived to be due to fatalistic reasons, people are likely to adopt individual action of 'do nothing'. (b) When disadvantage is perceived as due to individual character people will use individual action. (c) Where perception of causes of disadvantage or poverty becomes structural people are likely to engage in collective action. These propositions are reformulated as follows, as the hypotheses for the present study. It was therefore hypothesised that respondents' choice of action is contingent upon their attributions of poverty regardless of strength or nature of feelings of injustice. When predominant attribution of poverty is individual, resulting action will be individual regardless of feelings. Similarly, when attribution is fatalistic or individual, resultant action will also be individual. However, where attribution of poverty is structural, resultant action will be collective, regardless of strength or nature of feelings of injustice. In the same vein, where poverty attribution is fatalistic or individual, respondents will be unwilling to embark on collective action. However, where attribution is structural, respondents will be more willing to engage in collective action.

\section{Research Method}

Data was derived from questionnaires administered on residents of Badia community. Using the Raosoft sample size calculator online, based on the estimated population of Badia of Badia is 120,000 (NPC, 1997), at a standard error margin of $5 \%$, a confidence level of $95 \%$, and a $50 \%$ response distribution, a sample size of 383 was electronically calculated. Data was collected using a questionnaire. Section $A$ of the questionnaire required respondents $(n=383)$ to rate 38 items on causes of poverty on a Likert scale of 1 to 5 , (where $1=$ strongly disagree and $5=$ strongly agree), using Feagin's (1972) original Causes of Poverty Scale (CPS). Section B required respondents to rate 30 items related to three variants of the feeling of injustice namely; Relative Deprivation (RELDEP), Income Inequality Aversion (INEQUAV) and System Blaming (SYSBLAME) as a reflection of their feelings about the situation in Nigeria. Responses were on a Likert scale of 1 to 5 , (where $1=$ strongly disagree and $5=$ strongly agree. Section, $C$, required respondents to indicate which of 30 actions they had taken in the preceding year in reaction to the conditions of life in Nigeria, also on a Likert scale of 1 to 5 where $1=$ never and $5=$ very often.

\subsection{Data Analysis Techniques}

Data analysis was done using the SPSS programme. The factor analytical approach was used for the poverty attribution 
dimension. Thus the Principal Components Analysis (PCA) procedure was adopted to reduce multiple items into a few scales. Furthermore, Multivariate Analysis of Covariance (MANCOVA) was used for mediation analysis because it fits well into the FSM, which is the conceptual model for the study. The MANCOVA which performs the same function as the regression was chosen to test the hypothesis because unlike the regression, MANCOVA can examine many dependent variable simultaneously, which was a requirement for the test of the hypothesis for the study given that five categories of action (exit, individual normative, individual non normative, collective normative and collective non normative) were the dependent variables.

\subsection{Variables and Subscales}

\subsubsection{Standardized Feelings of Injustice (STANFI) Scale}

In order to derive a measure the feeling of injustice, a Standardized Feelings of Injustice Scale (STANFI) was derived to combine the effects of three widely used measures of the feeling of injustice namely Relative Deprivation (RELDEP), Income Inequality Aversion (INEQUAV) and System Blaming (SYSBLAME). While the RELDEP scale measured more general feelings relating to living conditions and SYSBLAME measured general attitudes to the governing apparatus, INEQUV evaluated attitudes towards income inequality specifically. This scale is consistent with specification in the literature as optimal measures of RD often included both an intergroup comparison and an affective element (Beaton \& Deveau, 2005: 1616). The STANFI scale is valid and reliable with a Cronbach's alpha of 0.87, mean $=74.30, S D=2.68$. In order to derive STANFI, the total scores for each respondent were combined for the all three items that showed the highest means for each sub-scale (RELDEP, INEQUAV and (SYSBLAME). The means of the total three scores were further added and divided by the total number of items, and feelings of injustice were conceptualized as low, medium or high depending on the mean score derived for each respondent. 'Low' mean scores were coded as 1, 'moderate' as 2, and 'strong' scores were coded as 3 into the SPSS programme as individual STANFI scores.

\subsubsection{Poverty Attribution (PREFAT) Scale}

The poverty attribution sub-scales were computed using two approaches. In the first stage, PCA was carried out on 38 items on various causes of poverty derived from earlier studies. Responses $(n=383)$ were measured on a Likert scale of 1 to 5, where 1= Strongly Disagree and 5= Strongly Agree. Factor analysis reduced items imputed into three distinct factors that were named Individualism, Fatalism and structuralism, consistent with the main path in the poverty attribution literature (Feagin, 1972). The Scale was 'very good' with a KMO $=0.80$ (see table 5.2). As most respondents chose more than one form of attribution indicating 'dual/split consciousness' (Mann, 1970) it became necessary to derive which causal attribution of poverty each respondent favoured. To achieve this, the extent of acceptability of each form of explanation was calculated for each respondent using the transform by computation command in SPSS.

Total scores of each respondent on the 12 items on the individualistic subscale, 12 on the structural subscale and 13 items on the fatalistic subscale were added and total scores of each respondent were divided by the number of items in each subscale. In this way, mean Individual (MEANIND), mean Structural (MEANSTR) and mean Fatalistic (MEANFAT) scores were generated for each respondent. Subsequently, MEANIND, MEANSTR and MEANFAT were compared for each respondent and respondents' PREFAT was taken to be the attribution category in which they obtained the highest mean score. Cronbach's alpha test for the 25 items used for the second PCA and further analysis showed a reliability of 0.68 , approximately 0.7 which is 'acceptable'.

\subsubsection{Preferred Action (PREFACT) Scale}

PREFACT determined the preferred action each respondent took in reaction to deprivation. The preferred action for each respondent was taken as the action in which the respondent accumulated the highest comparative mean rating. Reactions were conceptualized using Wright et al.'s (1990) classification of possible reactions which include 'Do nothing', 'Individual Normative action', 'Individual Non-Normative action', 'Collective Normative action' and 'Collective NonNormative action'. As actions measured were conceptualized as action already take, 'do northing' in Wright et al.'s typology was replaced with Hirschman's (1973) 'exit' and operationalized as 'exit attempt' as respondents who may have exited would not be available during the survey as may be obtainable in an experimental situation. To compute PRERACT, mean ratings of each reaction types per respondent were obtained using the 'compute-by- transformation' function in the SPSS programme. 
The total scores for each respondent on questionnaire items relating to each reaction type were computed and divided by the total number of items in each category. In this way, the following were obtained for each respondent; mean Individual Normative (MEANINA), mean Individual Non-Normative, (MEANINNA), mean Collective Normative (MEANCNA) and mean Collective Non-Normative (MEANCNNA). As exit attempt was derived using only one item, its score for each respondent was regarded as each respondent's mean score on the item. Subsequently, mean scores on each action type were compared for each respondent and the action type where respondents received the highest mean scores were regarded as their preferred action (PREFACT). Cronbach's alpha tests on the items combined however show that as a group the action categories were adequate measures of action. Cronbach's alpha for the scale $($ PREFACT $)=0.72$, mean $=45.02, \mathrm{SD}=7.59$.

\section{Results}

The test of mediation effect of poverty attribution on the relationship between the standardized feelings on Injustice scale (STANFI) and the means of the five preferred action categories (exit, individual normative, individual non normative, collective normative and collective non normative) was done by conducting a $5 \times 1 \times 3$ MANCOVA using each of fatalistic, individual and structural attributions as mediators in succession. In the first order of analysis, a MANOVA was conducted to find the main effect of STANFI on all action categories. The result shows that STANFI significantly predicts all action categories in all four multivariate tests at 0.01 level of significance; Pillai's test- $F(383)=2.56, p<0.01$; $=.211$; Wilk's Lambda- $F(383)=4.18, p<0.01$; Hoteling's Trace $-F(383)=7.22, p<0.01$ and Roy's Largest Root $-F(383)=$ 18.86, $p<0.01$. Post- hoc test of between subject effects shows a significant effect of STANFI on collective normative action $F(383)=19.83, p<.01$. There was no other significant effect. Subsequently, fatalistic attribution was added to the equation. The addition of fatalistic attribution did not alter the result of multivariate tests as all tests remain significant $p<$ 0.01 . However, post hoc test of between subject effects showed that fatalism had additional significant positive effect of STANFI on individual normative action, $F(383)=1.50 p<0.01$ and individual non normative, $F(383)=6.55, p<0.01$. This result supports the sub-hypothesis that as fatalistic attributions increases, individual normative and individual non normative action increases, signifying appositive relationship. However, fatalistic attribution showed no significant main effects on collective normative or collective non normative action.

Result therefore confirms the proposition that while structural attribution contributed to collective action, fatalistic attribution has the very opposite effect. This result is in line with the five stage model of intergroup relation (Taylor \& Mckirnan, 1984); it is only in the fifth stage where group members are conscientized that collective action will be taken. In earlier stages, where individual and fatalistic attributions predominated, actions were predominantly individual. Taylor et al., (2001; 268) found a similar empirical support when they found that respondents in the closed-unjust conditions preferred collective action, while those whose evaluations are just, preferred individual action. They also found that respondents in the far from gaining entry condition adopted an attitude of defeat. They interpreted this to mean that these ones accepted their fate; this pattern of action was equally reported by Wright et al., 1990). While attributing this result to ethnically disadvantage groups who accept low status, Taylor et al. (2001: 270) concluded that; ' ...the injustice robs them of personal control over their situation'. The structural explanation therefore sheds light upon the conditions under which collective responses will be preferred over individual ones, therefore contributing to the movement from reductionism to greater emphasis on collective responses (Taylor et al., 2001; Taylor \& Moghaddam, 1987).

The test of mediation effect of poverty attribution on the relationship between STANFI and the five preferred action categories (exit attempt, individual normative, individual non normative, collective normative and collective non normative) was conducted with the aid of a $1 \times 3 \times 5$ MANCOVA using each of fatalistic, individual and structural attributions as mediators in turn succession. In the first stage of the analysis, MANOVA elicited the main effect of STANFI on all action categories. The result (see table 1) shows that SANFI significantly predicts all action categories in all four multivariate tests $(p<0.01)$; Pillai's test: $F(383)=2.56, p<0.01$; Wilk's Lambda: $F(383)=4.18, p<0.01$; Hoteling's Trace: $F(383)$ $=7.22, p<0.01$ and Roy's Largest Root: $F(383)=18.86, p<0.01$. Post- hoc test showed a significant effect of STANFI on collective normative action $F(383)=19.83, p<0.01$. However, there was no other significant effect. Afterward, fatalistic attribution was added to the equation.

The addition of fatalistic attribution did not alter the result of multivariate tests as all tests remained significant $p<$ 0.01 . However, post hoc test (of between subject effects) showed that fatalism had additional significant positive effect of STANFI and individual normative action, $F(383)=1.50 p<0.01$ and individual non normative, $F(383)=6.55, p<0.01$. This result indicates that as fatalistic attributions increases, individual normative and individual non normative actions increase at all levels of feelings of injustice, signifying a positive relationship. However, fatalistic attribution showed no significant main effects on collective normative or collective non normative action. 
Table 1: Main effect of Fatalistic Attribution on Feelings of Injustice and Action

\begin{tabular}{|l|l|c|c|c|c|c|}
\hline Source & Dependent variables & SS & Df & MS & F & Sig. \\
\hline \multirow{5}{*}{ STANFI } & Exit & 6.003 & 93 & .065 & .966 & .569 \\
& Individual Normative & 68.506 & 93 & .737 & 1.495 & .000 \\
& Individual Non normative & 49.30 & 93 & .530 & .6 .552 & .000 \\
& Collective Normative & 18.201 & 93 & .196 & 18.788 & .136 \\
& Collective Non Normative & 2.136 & 93 & .023 & 1.123 & .234 \\
\hline
\end{tabular}

${ }^{*} p<.005$

In the second stage of the regression analysis (see table 2), the added effect of individual attribution on STANFI and action categories was tested. Result showed that individual attribution did not show any statistically significant additional main effect on the equation as the tests for all dependent variables showed the same levels of significance; individual normative, $F(383)=1.52, p<0.0$ '81; individual non normative, $F(383)=5.77, p<0.01$. This shows that fatalistic and individual attributions have similar effects on respondents' actions at the same level of feelings of injustice.

Table 2: Main effect of Individual Attribution on Feelings of Injustice and Action

\begin{tabular}{l|l|c|c|c|c|c|}
\hline Source & Dependent variables & SS & Df & MS & F & Sig. \\
\hline \multirow{5}{*}{ STANFI } & Exit & 5.8 & 93 & .063 & .937 & .637 \\
& Individual Normative & 68.46 & 93 & .736 & 1.52 & .000 \\
& Individual Non normative & 44.82 & 93 & .482 & 5.77 & .000 \\
& * $p<.005$ & 1.19 & 93 & .196 & 1.715 & .091 \\
& Collective Normative & 2.08 & 93 & .022 & 1.091 & .292 \\
\hline
\end{tabular}

At the last stage of the analysis, when structural attribution was added to the equation (see table 3 ), in addition to the statistical significance of individual normative, $F(383)=1.60, p<0.01$, and Individual non normative, $F(383)=1.37, p<$ 0.01 , structural attribution showed a significant main effect on collective normative action, $F(383)=18.16, p<0.01$. However, all relationships with collective non-normative action remained insignificant despite the introduction of all subdimensions of poverty attribution.

Table 3: Main effect of Structural Attribution on Feelings of Injustice and Action

\begin{tabular}{|l|l|c|c|c|c|c|}
\hline Source & Dependent variables & SS & Df & MS & F & Sig. \\
\hline & Exit & 5.845 & 93 & .063 & .936 & .640 \\
& Individual Normative & 62.78 & 93 & .675 & 1.602 & .000 \\
STANFI & Individual Non normative & 44.785 & 93 & .482 & 1.378 & .000 \\
& Collective Normative & 17.719 & 93 & .191 & 18.16 & .000 \\
& Collective Non Normative & 2.186 & 93 & .024 & 1.192 & .139 \\
\hline${ }^{*} \mathrm{p}<.005$
\end{tabular}

\section{Discussion}

The result from the present study contributes empirical support to the FSM by showing that the stages of the FSM are analogous to the different stages in which causal attributions proceed. The results showed that where attributions were fatalistic as analogous to the first stage of the FSM, resultant action was individual normative. In the next stage where attributions are individual, the disadvantaged retained individual normative actions. However, where individual actions and normative attempts at breaching group boundaries fail, people realize that continued pursuit of individual action is futile and the perception of basis for selection into advantaged group as contingent upon personal efforts is replaced with the perception that the overriding social philosophy is faulty. At this point, individual attribution is substituted for structural attribution. It is only where structural attributions predominate and conscientization occurs that the disadvantaged show interest or willingness to engage in collective action or actually pursuing this alternative. The five stage model guided the way statistical analysis was conducted in the present study. Given that attributions are usually layered (Mann, 1970; Bobo, 1991) and that in this study all respondents rated more than one causal attribution, the hierarchical regression model tested willingness to embark on collective action, with each attribution sub-dimension added to the equation in 
succession. In this way a path equation encompassing all dimensions was derived. Where dependent variable was action, a single MANCOVA equation accommodating all five categories of action as dependent variables in one path model showed that fatalistic and individual attributions predict respondents' participation in individual action. However, at the stage where structural attribution was included, a significant main effect was derived on collective normative action. However, like in many past studies (e.g. Martin, 1996; Wright et al., 1990), the emergent path model was unable to predict collective non-normative action.

The MANCOVA equation showed a significant main effect of structural attribution on collective action, it was unable to predict collective non normative action. Initially this was adduced to dual/split consciousness and a counter hypothesis that if the equation was constructed holding layering of attribution constant, the result might predict nonnormative action. However, given the paucity of responses to questionnaire items relating to collective non-normative action, an alternative statistical equation was doomed for futility as the number of responses would have created empty cells in the analysis and hampered analytical tools (Shek, 2003).

The findings of this study situates well within the literature. While the FSM provided the theoretical springboard upon which the analysis and argument of the study is made, the results are fitted into the general framework of reaction to inequality among disadvantaged groups and persons. Unlike past models biased toward conceptualizations of collective action, the present model shows how action pursued is determined by the nature of attributions held in light of the FSM's conception of action in stages. RM based research has been predicated upon the premise that deprivation and inequality translate into action whenever resources are available, without regards to feelings (McCarthy \& Zald, 1977). While this assertion has received empirical support (e.g. Ellemers et al., 1993), the result from the present study contradicts RM in the sense that it showed that injustice feelings are salient within the framework of action. The result showed that feelings of injustice that while feelings of injustice do not directly predict action, where feelings of injustice are mediated by structural attribution, collective normative action ensued, confirming FSM's prediction that conscientization consequent upon failed attempts to breach group boundaries, overturns prevalent social philosophies guiding stratification making disadvantaged persons and groups amenable to collective responses (Wright et al., 1990; Taylor et al., 2001; Taylor \& Moghaddam, 1987).

The results propose that responses to disadvantage and inequality proceed through FSM's sequential stages through which disadvantaged groups' responses to inequality passes in sequence. The stages are marked by changes in perception of disadvantaged group members of the overriding social philosophy guiding stratification (Wright et al., 1990; Taylor \& Moghaddam, 1987). In the first stage, stratification is guided by ascription; at this stage, group members are fatalistic in attribution and thus they adopt individual normative action and are unwilling to take collective action. In the second stage, overriding social philosophy becomes individual as people are motivated to believe that disadvantage is the result of individual inadequacy; poverty attribution in this stage is thus individual and individual normative action is retained. At the third stage selected members of the disadvantage groups attempt mobility. However, when these attempts fail and the perception that entry to privileged group is closed, conscientization occurs (4th stage), and overriding philosophy of individualism is jettisoned thus relations arrive at the fifth stage where structural attribution becomes dominant and collective action becomes possible. While studies have shown that reaction to injustice encompasses an array of actions from passive acceptance to collective protest (Wright et al., 1990; Louis \& Wright, 2002), most have reported stronger preferences for individual action regardless of whether deprivation is individual or group based. The only exception has been Boen \& Vanbeselaere (1998).

Poverty attribution therefore represents a distinct path to action from identification and instrumental cost benefit considerations, both of which have been at the core of SIT's arguments. While fatalistic and individual attributions leads a sub-path to individual action, a structural pathway is linked in the second sub-path to collective action along with SIT's efficacy, emotion and identification and RM's costs-benefit calculation. The salience of structural attribution in the action matrix is based on the added variance reported in statistical analysis of structural attribution to action in the MANCOVA equation. Following Bluic et al (2007), this study shows that variance contribution to action is not limited to instrumental and affective considerations. This has been the conclusion of many recent studies (e.g. van Stekelenburg et al., 2009; Ginges \& Altran, 2009).

\section{Conclusion}

The failure of SIT to predict which group members would embark on collective action led to the development of an integrative perspective culminating in FSM's proposal that changes in perception of social philosophy guiding stratification and income distribution determines type and nature of resultant action (Taylor \& Mckirnan, 1984; Taylor \& Moghaddam, 1987). While FSM- inspired studies have theorized action to be the result of perception of group openness and 
legitimacy, there is little attention to FSM's proposition that the true determinant of action is the change in the social philosophy guiding stratification even if perception of openness of group boundaries can be therein deduced. However, while scholars agree with the basic argument of RD that deprivation often stimulates feelings of injustice, Martin (1986) argued that often feelings have not led to action. Scholars have therefore been interested in studying what factors motivate or hinder reaction to injustice. While many, using the paradigm proposed by SIT, have identified instrumental and affective '8pathways to action, there have been arguments for the inclusion of separate pathways of emotions (Stürmer \& Simon, 2009), individual self enhancement (Tropp \& Brown, 2004) as well the protection of sacred values (Ginges \& Altran, 2009). Bluic et al's (2007) argument that the statistical variance contributed to action by these variables justifies the search for non-instrumental antecedents accounting for missing variance in action.

The introduction of a poverty attribution pathway, therefore introduces an analysis of the effects of consensually held beliefs in shaping action in line with recent trends related to the renewed reckoning of frames that spur micromobilization (Rothenberg et al., 2008). The present study therefore contributed to the debate about antecedents of action by showing that poverty attribution is one of the variables that account for 'missing variance' in action. The study hypothesizes on the basis of previous findings indicating that attributions influence predispositions (Pandey et al., 1992) and actions as well as willingness to assist the poor or participate in anti-poverty activities. Poverty attributions have also been proposed to be useful in determining reaction to injustice and deprivation and consequently for micro mobilization of the poor to counter hegemonic forces (Bullock, 2006; Harper, 2003).

\section{References}

Beaton, A.L. \& Deveau, M. (2005). Helping the less Fortunate: A Predictive Model of Collective Action. Journal of Applied Social Psychology, 35(8): 1609-1629.

Bliuc, A., McGgarty, C., Reynolds, K. J. \& Muntele, D. (2007). Opinion-Based Group Membership as a Predictor of Commitment to Political Action. European Journal of Social Psychology, 37: 19-32.

Bobo, L. (1991). Social Responsibility, Individualism, and Redistributive Policies. Sociological Forum 6: 71-91.

Boen, F. \& Vanbeselaere, N. (1998). Reactions upon a Failed Attempt to enter a High Status Group: An Experimental Test of the FiveStage Model. European Journal of Social Psychology, 28: 689-696.

Boen, F., \& Vanbeselaere, N. (2000). Responding to Membership of a Low-Status Group: The Effects of Stability, Permeability and Individual Ability. Group Processes \& Intergroup Relations, 3: 41-62.

Boen, F., \& Vanbeselaere, N. (2002). The Relative Impact of Socio-Structural Characteristics on Behavioral Reactions against Membership in a Low-Status Group. Group Processes \& Intergroup Relations, 5: 299.

Bullock, H. (2006). Justifying Inequality: A Social Psychological Analysis of Beliefs about Poverty and the Poor. National Poverty Centre Working Paper Series 06-08. Downloaded at: http://www.npc.umich.edu/publications/working_papers/

Crosby, F. (1976). A Model of Egoistical Relative Deprivation. Psychological Review, 83: 85 - 113.

Della Fave, L.R. (1974). On the Structure of Egalitarianism. Social Problems, 22: 199-213.

Edelman, M. (1998). Language, Myths and Rhetoric. Society, 35: 131-139.

Ellemers, N., Wilke, H. \& Van Knippenberg, A. (1993). Effects of the Legitimacy of Low Group or Individual Status on Individual and Collective Identity Enhancement Strategies. Journal of Personality and Social Psychology, 64: 766-778.

Feagin, J. (1972). Poverty: We still believe that God helps them who help themselves. Psychology Today, 6: 101-129.

Foster, M. \& Matheson, K. (1995). Double Relative Deprivation: Combining the Personal and Political. Personality and Social Psychology Bulletin, 21: 1167-1177.

Giguère, B. \& Lalonde, R.N. (2010). Why do Students Strike? Direct and Indirect Determinants of Collective Action Participation. Political Psychology, 31(2): 277-247.

Ginges, J. \& Atran, S. (2009). What Motivates Participation in Violent Political Action: Selective Incentive or Altruism? Annals of New York Academy of Science, 1167:115-123.

Gurr, T.R. (1970). Why Men Rebel. Princeton, N.J.: Princeton University Press.

Harper, D.J. (2003). Poverty and Discourse: In: S. Carr \& T.S. Sloan (eds.) Poverty and Psychology: From Global Perspective Local Practice. New York: Kluwer-Plenum.

Jackson, R. (1987). Prosperity Theology and the Faith Movement. Themelios, 15:19-24.

Kelly, C. \& Breinlinger, S. (1996). The Social Psychology of Collective Action: Identity, Injustice, and Gender. London: Taylor \& Francis.

Klandermans, B. (2002). How Group Identification Helps to Overcome the Dilemma of Collective Action. American Behavioral Scientist, 45: 887-900.

Lalonde, R.N. \& Silverman, R.A. (1994). Behavioural Preferences in Response to Social Injustice: The Effects of Group Permeability and Social Identify Salience. Journal of Personality and Social Psychology, 66: 78-85.

Lepianka, D., Oorschot, W. \& Gelissen, J. (2009). Popular Explanations of Poverty: A Critical Discussion of Empirical Research. Jnl Soc. Pol., 38(3): 421-438.

Mann, M. 1(970). The Social Cohesion of Liberal Democracies. American Sociological Review, 35: 423-39.

Martin, J. Brickman, P. \& Murray, A. (1984). Moral Outrage and Pragmatism: Explanations for Collective Action. Journal of Experimental 
Social psychology, 20: 484-496.

Martin, J. 1986. The Tolerance of Injustice; in J. Olsen, C. Herman \& M. Zanna (eds.) Relative Deprivation and Social Comparison: The Ontario Symposium, vol. 4, (pp. 217-242). Hillsdale, NJ: Erlbaum.

McCarthy, J.D. \& Zald, M.N. (1977) Resource Mobilization and Social Movements: A Partial Theory. American Journal of Sociology, 82: 1212-1241.

Moghaddam, F.M. Taylor, A.M. \& Lalonde, R.N. (1987). Individualistic and Collective Integration Strategies among Iranians in Canada. International Journal of Psychology, 22: 301- 313.

Mummendey, A., Kessler. T., Klink, A. \& Mielke, R. (1999). Strategies to Cope with Negative Social Identity: Predictions by Social identity Theory and Relative Deprivation Theory. Journal of Personality and Social Psychology, 76: 229-245.

NPC (1997). National Population Commission, Nigeria. Population Projections, 1996.

Olson, M. (1968). The Logic of Collective Action. Public Goods and the Theory of Groups. Cambridge, MA: Harvard University Press.

Pandey, J., Sinha, Y., Prakash, A. \& Tripathi, R. (1982). Right-Left Political Ideologies and Attribution of the Causes of Poverty. European Journal of Social Psychology, 12: 327-331.

Robinson, J. W. 2009. American Poverty Cause Beliefs and Structured Inequality Legitimation. Sociological Spectrum, 29: 489-518.

Rothenberg, S. \& Scully, M. \& Zang, T. (2002). Mobilization of the Wealthy to Contest Income Inequality. Paper Presented at the 13th Annual International Association of Business and Society, Victoria, British Columbia, Canada.

Runciman W G. (1966). Relative Deprivation and Social Justice. London: Routledge \& Kegan Paul.

Shek, D. (2003). Chinese People's Explanations of Poverty: The Perceived Causes of Poverty Scale. Research on Social Work Practice, 13(5): 622-640.

Stürmer, S. \& Simon, B. (2009). Pathways to Collective Protests: Calculations, Identification, or Emotion? A Critical Analysis of the Role of Group-Based Anger in Social Movement Participation. Journal of Social Issues, 65(4): 681-705.

Suhrecke, M. (2001). Preferences for Inequality: East v West. Innocenti Working Papers 89. UNICEF, Florence.

Szirmai, A. (1991). Explaining Variations in Attitudes toward Income Inequality. In: H. Steensma \& R. Vermunt (eds.) Social Justice in Human Relations: social and Psychological Consequences of Justice and Injustice, vol. 2 (pp. 229-268). New York and London: Plenum Press.

Tajfel, H., \& Turner, J. (1979). An Integrative Theory of Intergroup Conflict. In: W.G. Austin, \& S. Worchel (eds.) The Social Psychology of Intergroup Relations (pp. 33-37). Monterey, CA: Brooks/Cole.

Taylor, D.M. \& Mckirnan, D.J. (1984). A Five Stage Model of Intergroup Relations. British Journal of Social Psychology, 23: 291-300.

Taylor, D.M. \& Moghaddam, F.M. (1987). Theories of Intergroup Relations. New York: Praeger.

Taylor, D.M., Moghaddam, F.M., Gamble, I. \& Zellerer, E. (2001). Disadvantaged Group Response to Perceived Inequality: From Passive Acceptance to Collective Action. Journal of Social Psychology, 127(3): 259-272.

Tropp, L.R \& Brown, A.C. (2004). What Benefits The Group Can Also Benefit The Individual: Group Enhancing And Individual Enhancing Motives For Collective Action. Group Processes Intergroup Relations, 7: 267-282.

van Stekelenburg, J. Klandermans, B. \& van Dijk, W. (2009). Context Matters: Explaining how and why Mobilizing Context Influences Motivational Dynamics. Journal of Social Issues, 65: 815-838.

van Zomeren, M., Leach, C.W., \& Spears, R. (2010). Does Group Efficacy Increase Group Identification? Resolving the Paradoxical Relationship. Journal of Experimental Social Psychology, XXX: 1-6.

Wright, S., Taylor, D. \& Moghaddam, F. (1990). Responding to Membership in a Disadvantaged Group: From acceptance to Collective Protest. Journal of Personality and Social Psychology, 6: 994-1003. 